\title{
O princípio de coesão territorial enquanto novo paradigma de desenvolvimento na formulação de políticas públicas: (re)construindo ideias dominantes
}

Gonçalo Santinha. Universidade de Aveiro, Aveiro, Portugal.

RESUMo | A valorização da dimensão territorial na formulação de políticas públicas tem sido visível nas orientaçóes emanadas pelas mais diversas instituiçóes mundiais, lançando recentemente para o debate político e acadêmico a Coesão Territorial enquanto novo paradigma de desenvolvimento. Num momento de particular importância, em que se discutem as orientaçôes para o período pós-2013 e a atribuição dos fundos estruturais, esta questão assume um interesse adicional nos EstadosMembros da União Europeia. Embora, como objetivo político, a Coesão Territorial tenha vindo a adquirir uma importância elevada, ainda é notória a ausência de uma delimitaçáo precisa do conceito, dificultando a capacidade de lidar de forma analítica e normativa com este princípio. É sobre esta questão que o texto se debruça, identificando-se caminhos que poderão contribuir como referencial para a formulação e territorialização de políticas públicas, melhorando, assim, os processos de decisão com base neste princípio.

PALAVRAS-CHAVE | desenvolvimento territorial, distribuição espacial, integração territorial.

ABSTRACT | There has been a growing interest by several worldwide institutions in both academia and policy making arenas in the territorial dimension of public policy design, discussing the added value of Territorial Cohesion as the new development paradigm. In a stage of particular importance, in which the main guidelines for the post-2013 period and the allocation of structural funds are being discussed, this issue assumes an additional interest amongst the European Union Member-states. Albeit as a political objective Territorial Cohesion is here to stay, there is no agreement on its precise meaning, hence raising difficulties on how to deal with it in an analytical and normative way. This article seeks to bring critical commentary to this arena on this matter by providing a guiding reference for public policies design and territorialization, thus improving decision policy processes based on this principle.

KEY WORDS | territorial development, spatial distribution, territorial integration.

Recibido el 22 de agosto de 2011, aprobado el 1 de noviembre de 2012

E-mail: g.santinha@ua.pt 


\section{Introduçáo}

De uma forma crescente, a dimensão territorial vem assumindo visibilidade na formulação de políticas públicas. A título de exemplo, uma análise dos trabalhos produzidos pela Organização para a Cooperação e Desenvolvimento Econômico (ocDE, em inglês, Organisation for Economic Cooperation and Development) (2001, 2009) ou pelo Banco Mundial (2009), mostra como estas instituiçóes, de referência em escala mundial, sublinham a importância de abordagens de base territorial como fatores essenciais na formulação de políticas públicas. No quadro concreto das políticas da Comissão Europeia (CE), esta questão é igualmente visível, tendo sido inclusive adotado, recentemente, o princípio da Coesão Territorial (Ст) como o novo paradigma de desenvolvimento do território europeu.

A noção de Ст advém de um dos conceitos pilares da Política Regional -o da "coesão"- que, ausente do Tratado de Roma (1957), emerge formalmente em 1986 no Acto Único Europeu, fazendo da Coesão Econômica e Social uma nova competência da Uniáo Europeia (UE) com o intuito de se promover o desenvolvimento harmonioso do território Europeu. Mas é só com o Tratado de Amsterdã (1997) que surge, pela primeira vez, o conceito de Cт num texto oficial. Se é certo que este surge formalmente neste Tratado, com o principal intuito de moderar os efeitos associados à (tendência de) liberalizaçáo dos Serviços de Interesse Geral (Faludi, 2010), não é menos verdade que há quatro episódios institucionais recentes que marcam um ponto de não retorno na adoção deste princípio, do ponto de vista $\mathrm{da}$ política pública: a publicação da Agenda Territorial da União Europeia (primeiro, em 2007, e a versáo renovada, em 2011), o lançamento do Livro Verde sobre a Coesáo Territorial (2008), a inclusão da CT no Tratado de Lisboa (2009) enquanto $3^{\circ}$ pilar de atuação a par da Coesão Econômica e da Coesão Social e, finalmente, o desenho da Estratégia Europa 2020, adotada em 2010, com o intuito de relançar a economia europeia e na qual a Ст surge como um dos principais objetivos a atingir.

Procurando incutir a importância do território na agenda política, o princípio da Cт surge, no seio destas orientaçóes, com o intuito generalizado de alcançar o desenvolvimento harmonioso de todos os territórios (ou seja, um desenvolvimento socioeconômico equilibrado e equitativo), valorizar a sua diversidade e complementaridades, e facultar a possibilidade da população tirar o melhor partido das características existentes em cada território. Embora o Livro Verde e a abertura do processo de consulta pública sobre o mesmo procuraram clarificar o que se entendia por CT e quais as políticas a tomar para se alcançar esse princípio, ainda se verifica alguma ambiguidade inerente ao seu conceito (o quê) e à sua operacionalizaçáo (como). Esta é, precisamente, uma preocupaçáo que vem emergindo nos últimos anos em diversos países, cujas orientaçóes, claramente influenciadas pela agenda da CE, apontam no sentido de adotar este princípio na formulação de políticas públicas.

É justamente sobre esta ausência de delimitação precisa do conceito e sobre o seu valor acrescentado, enquanto princípio integrante da formulaçáo de políticas públicas, que este texto se debruça, identificando-se alguns caminhos que poderão contribuir para a melhoria dos processos de decisão e para a própria territorialização das políticas públicas. $\mathrm{O}$ texto inicia com uma panorâmica das políticas públicas 
no espaço europeu, com o intuito de clarificar o caminho traçado até a adoção da Ст enquanto novo paradigma de desenvolvimento. No seguimento desta narrativa histórica, elencam-se as razóes que justificam a adoção deste princípio no contexto atual. Os argumentos expostos constituem o ponto de partida da terceira seção, na qual se procura apresentar uma interpretação processual do princípio de CT, para que se possam formular políticas públicas que caminhem no sentido de operacionalizá-lo e promovê-lo. Por fim, na última seção, é apresentado um quadro síntese do exercício efetuado que poderá beneficiar, quer futuros debates no âmbito desta temática, quer os próprios processos de tomada de decisão política, num momento de particular importância em que se discutem as orientaçóes para o período pós-2013.

\section{A dimensão territorial nas políticas públicas: rumo à coesão territorial}

Desde sua origem, que a UE tem por missão promover um desenvolvimento harmonioso das atividades econômicas pela redução das disparidades entre as diversas regióes e do atraso das menos favorecidas (Tratado de Roma, 1957). Uma missáo que adquiriu uma maior relevância por intermédio de Jacques Delors em 1986 com a adoção do Acto Único Europeu, estabelecendo uma política comunitária de coesão econômica e social a fim de contrabalançar os efeitos da realização do mercado interno nos Estados-Membros menos desenvolvidos, e de atenuar as discrepâncias de desenvolvimento entre as regióes. Sem alterar a base e os objetivos da sua gênese, com o passar do tempo esta política foi sendo redesenhada: se, numa fase inicial, a sua concretização na procura da diminuição das assimetrias regionais efetuava-se com base numa distribuição equitativa dos fundos comunitários, mais tarde, constatou-se que nem sempre isso aconteceu (Santinha, Rodrigues \& Almeida, 2009). Os trabalhos desenvolvidos por Martin (2003) e pela própria CE (European Commission, 2008) são esclarecedores desta questão, mostrando que, ao longo dos tempos, embora as desigualdades entre Estados-Membros tenham diminuído (em valores de PIB per capita), as disparidades entre regióes NUTS II dentro de cada Estado-Membro aumentaram, contrariando assim, os objetivos de base para os quais a Política de Coesão foi desenhada. Surgindo formalmente com o Tratado de Amsterdã (1997), a Cт vem dar corpo a esta preocupação com as disparidades, procurando incutir a importância do território na agenda política, não só europeia, mas também de cada Estado-Membro: territory matters é uma expressão que passa a ser recorrente nas diversas políticas e relatórios de orientação comunitária.

Este recrudescimento do interesse na dimensão territorial das políticas públicas advém muito do trabalho desenvolvido desde a década de 90, no âmbito do ordenamento do território, evidenciando o quão importante pode ser para se atingirem os objetivos de coesáo tendo em conta a diversidade territorial no espaço europeu (Ionica, 2007). Sem competência formal na CE, em matéria do ordenamento do território, durante vários anos os defensores do princípio de CT optaram por uma estratégia didática, com uma dupla abordagem (Jouen, 2008): uma vertente prática/ operativa, através, por exemplo, do programa comunitário INTERREG -com uma visão de ordenamento transnacional-, e uma vertente mais conceitual, na procura de uma visão estratégica comum para o conjunto do espaço europeu, capaz de orientar 
as políticas públicas com impacto em todas as escalas (da europeia à local). Foi neste sentido que se sucederam um conjunto de estudos acadêmicos, como o Europe 2000 (1991), o Europe 2000+ (1994) e, em antecipação à entrada de 12 novos membros na UE, o EDEC: Esquema de Desenvolvimento do Espaço Comunitário, fator chave para "afirmar uma visão estratégica de ordenamento supranacional do território comunitário” (Ferrão, 2004, p. 48). Documentos aprovados, sublinhe-se, em reunióes informais por parte dos ministros do ordenamento do território e desenvolvimento regional dos Estados-Membros, pelo que quer o vocabulário adotado quer o conteúdo estratégico definido constituíram o resultado de um compromisso político.

Pela sua relevância para o ordenamento do território e pelo seu impacto político e científico, importa aqui destacar o EDEC, quer enquanto documento (e processo) chave em torno do próprio conceito de Ст, quer enquanto elemento demonstrador da importância da dimensão territorial nas políticas públicas. Amplamente reconhecido e mencionado na arena acadêmica e política, o EDEC representa um momento crítico na emergência de um novo discurso europeu sobre o ordenamento do território. Um processo de aprendizagem mútuo, desenhado por uma mistura de diferentes culturas de ordenamento do território e que contribuiu para uma alteração no método e na agenda das políticas de ordenamento do território (Albrechts, 2001), significando um deslocamento de abordagem típico de regulaçáo e uso do solo, para uma maior ênfase nas políticas e estratégias de ordenamento do território (Böhme, 1998). E, de fato, o EDEC constituiu um bom instrumento para os passos que se seguiram de forte cooperação entre diferentes atores, e enquanto encorajamento de novas formas de discussão, em que a dimensão territorial ganha importância na formulação de políticas públicas em diferentes níveis de decisão (comunitário, nacional e regional). As consequências do EDEC foram particularmente visíveis ao nível comunitário, quer do ponto de vista estratégico, quer numa perspectiva mais operacional, mas também, em alguns Estados-Membros as influências fizeram-se sentir.

Ao nível comunitário, ao "disponibilizar um referencial estratégico para o desenvolvimento do espaço europeu” (Ferrão, 2004, p. 50), o EDEC produziu impactos relevantes imediatos na elaboração de políticas comunitárias, e na aplicação dos fundos estruturais para o período 2000-2006. De fato, é notória sua influência no 20 Relatório sobre a Coesão Econômica e Social (2001), no qual é sublinhada a existência de disparidades territoriais no espaço europeu e feita uma referência explícita à questão da $\mathrm{CT}$, em consonância com o primeiro princípio diretor do EDEC - desenvolvimento espacial policêntrico e equilibrado na UE (Ferráo, 2004). Importa aqui mencionar o papel crucial que o Comissário Michel Barnier desempenhou neste processo, influenciando a adoção do princípio de CT em textos oficiais, como o $2^{\circ}$ Relatório ou, previamente, o Tratado de Amsterdã (1997). Sua adoção serviria inclusive, como "desculpa" para a CE ultrapassar o problema da falta de competências formais em matéria de ordenamento do território e, assim, atribuir oficialmente uma importância à dimensão territorial (Faludi, 2009). Ainda no campo da influência estratégica do EDEC, em termos de documentos e instituiçóes ao nível comunitário, é possível encontrar referências substanciais aos seus princípios no relatório seguinte da Política de Coesão (que, por sua vez, ia ganhando cada vez mais preponderância, como resposta a questóes inerentes às disparidades 
existentes e à integração de novos países), o $3^{\circ}$ Relatório sobre a Coesão Econômica e Social (2004), no qual é mencionado o desenvolvimento policêntrico e sublinhada a importância da Ст para o desenvolvimento do espaço europeu.

Por outro lado, ao apontar para a dificuldade existente na cooperação intersetorial das diferentes direções gerais da CE, e para a necessidade de uma articulação entre os diferentes níveis institucionais (desde a comunitária à local), o EDEC é referenciado no Livro Branco da Governança Europeia (CEC, 2001) enquanto um dos quadros orientadores para uma melhor coordenação entre as políticas setoriais da CE e dos Estados-Membros. Ainda mais relevantes sobre esta questão foram os resultados obtidos por Stead e Waterhout (2008), nas entrevistas que efetuaram nas várias direçóes gerais da $\mathrm{CE}$ sobre a influência do EDEC no seu modus operandi. A ideia geral é a de que o reforço da importância da dimensão territorial na formulação das políticas públicas, proporcionando consequentemente um maior número de questóes em comum e uma melhor divisão de responsabilidades, fortaleceu as ligaçóes entre as diferentes direçóes gerais.

Paralelamente a estas consequências comunitárias do ponto de vista estratégico, importa referir que o EDEC teve influência num âmbito de intervenção mais alargado (pan-europeu): a CEMAT (Conferência Europeia dos Ministros do Ordenamento do Território), criada em 1970, e constituída pelos representantes dos Estados-Membros do Conselho da Europa, aprova em 2000 o documento Guiding Principles for Sustainable Spatial Development of the European Continent, que "adota para todo o espaço europeu, com ligeiras adaptaçóes à especificidade dos países de leste, os princípios e a visão do EDEC" (Ferrão, 2004, p. 50). De uma forma geral, estes princípios orientadores têm como objetivo último, a harmonização entre as expectativas econômicas e sociais em relação ao território, contribuindo assim para um desenvolvimento territorial equilibrado. Refira-se, inclusive, que o primeiro dos dez princípios orientadores que elencava, visava à promoçáo da Ст por intermédio de um desenvolvimento econômico e social mais equilibrado das regióes e de uma maior competitividade.

Numa perspectiva mais operacional, o EDEC forneceu um excelente impulso para o desenvolvimento de dois instrumentos promotores da cooperação territorial, no âmbito da UE. Por um lado, verificou-se o lançamento, menos de um ano depois, da iniciativa INTERREG III nas suas três vertentes (transnacional, transfronteiriça e inter-regional), indicando uma forte influência do EDEC ao nível dos conceitos, princípios e estratégias (Stead \& Waterhout, 2008; Salez, 2009). Por outro lado, foi criado o European Spatial Planning Observatory Network (ESPON), que consiste num programa de investigaçáo que apoia a realizaçáo de estudos de base territorial, seja numa ótica de análise de disparidades territoriais, seja do ponto de vista da formulação de políticas mais adequadas ao desenvolvimento territorial da Europa. A experiência mostra que os estudos desenvolvidos no âmbito do ESPON (que, embora mantendo o mesmo acrônimo, curiosamente alterou a sua designação para Observation Network for Territorial Development and Cohesion, enfatizando, portanto, a questão da $\mathrm{CT}$ ) têm sido bastante úteis. Vejam-se, a título de exemplo, os estudos Territory Matters for Competitiveness and Cohesion (2006) e Scenarios on the Territorial Future of Europe (2007) que permitiram, por 
um lado, capitalizar informação bastante rica e diversa; por outro, sublinhar a importância da dimensão territorial na formulação de políticas públicas e, por fim, chamar a atenção para como determinadas tendências (desafios) - mobilidade e pressão migratória, envelhecimento demográfico, alteraçôes climáticas e eficiência energética, globalização e competitividade econômica, tecnologias de informação e comunicação e a crescente importância das cidades (enquanto atores globais) -, embora atingindo a UE na globalidade, afetam de forma diferenciada os territórios e, por conseguinte, constituem fatores catalisadores de disparidades territoriais. A lógica subjacente é a de que problemas comuns requerem soluçôes comuns, e a utilização de recursos comuns de forma harmonizada, tirando partido da diversidade territorial.

Finalmente, e embora com menor incidência, a influência do EDEC não se fez só sentir no nível das instituiçóes e documentos comunitários. Também teve consequências no nível nacional, apesar desta ter se verificado bastante variável e, na maior parte das ocasióes, muito limitada, fazendo-se sentir essencialmente em países onde as políticas de ordenamento do território foram reformuladas pouco tempo depois da sua publicação, como foram os casos da Grécia, da Espanha e de Portugal (espon, 2007).

É certo que a falta de competências formais no seio da CE, em matéria de ordenamento do território, torna a aplicabilidade de documentos da natureza do EDEC menos plausível. No entanto, o fato deste ter se revelado um processo longo e participativo (em parceria entre os diversos Estados-Membros e a $\mathrm{CE}$ ), fez com que a sua elaboração tenha se tornado mais importante do que o conteúdo do próprio documento (Albrechts, 2001; Ferrão, 2004). Este argumento baseia-se na ideia de que os atores e as instituiçóes não são meros recipientes passivos, que facilmente implementam o que os documentos propóem. Pelo contrário, são atores ativos num processo em que os conceitos e os objetivos estratégicos de documentos da natureza do EDEC náo são, à partida, uma preocupação desses mesmos agentes, pelo que processos de aprendizagem como os ocorridos durante a elaboração do EDEC e a adequação das suas propostas num âmbito mais vasto da agenda política europeia (isto é, servindo de fonte de inspiração), podem influenciar fortemente os processos de toma de decisão (Stead \& Waterhout, 2008). E, de fato, a dinâmica desencadeada pelo EDEC não só contribuiu para um maior reconhecimento do ordenamento do território, enquanto pré-requisito para o desenvolvimento harmonioso da Comunidade, para uma melhor integração das áreas mais periféricas e como meio necessário para uma maior racionalidade na afetaçáo de recursos (Atkinson, 2001), como também, serviu de base para o processo de elaboração e lançamento, em 2007, da Agenda Territorial da Uniáo Europeia, resultante de uma reuniáo intergovernamental informal dos diversos ministros do ordenamento do território da UE, e preparado conjuntamente com a CE.

Apresentado como um quadro político orientado para a açáo e promotor de cooperaçáo entre os Estados-Membros em matéria de ordenamento do território, e sustentado nos objetivos do EDEC, um dos grandes desígnios da Agenda Territorial consiste em reforçar a CT da UE e colocar o seu princípio no centro do discurso europeu. Sublinha, ainda, a importância de articular as orientaçóes de base territorial com as outras políticas da CE, designadamente a Estratégia de Lisboa e a Política 
de Coesão, para promover o bem-estar social e econômico do espaço europeu. Esta ideia resulta, essencialmente, do fato dos respectivos ministros terem percebido que a procura de Ст incluía o reforço da competitividade e a reduçáo das disparidades, argumentando que a Estratégia de Lisboa não tinha suficientemente em consideração o potencial da diversidade territorial europeia, pelo que abordagens integradas de desenvolvimento territorial (explorando o potencial endógeno existente), poderiam melhorar a sua prestaçáo e, consequentemente, aumentar a competitividade da Europa (Faludi, 2009).

Com o processo de elaboração do Tratado de Lisboa em mãos, e encorajada pela Agenda Territorial, a ce decidiu publicar, em 2008, o Livro Verde sobre a Coesão Territorial. Já com uma interpretação de ст que extravasa a tradicional abordagem de procura de convergência das regióes mais desfavorecidas, este documento enfatiza a necessidade de se tirar partido da diversidade e identidade territoriais, de maneira a fazer um melhor uso das suas características individuais específicas, através de mecanismos de cooperação. Por outro lado, no processo de reformas conduzidas pela CE, e já a pensar no pós-2013, a pedido da CE e da entáo Comissária para a Política Regional Danuta Hubner, o então Diretor-Geral do Ministério das Finanças e de Economia da Itália, Fabrizio Barca, desenvolveu o relatório Barca (2009), com o objetivo de apresentar propostas para o futuro da Política de Coesão. Nesse relatório, é visível a relevância da dimensão territorial na formulação de políticas públicas, argumentando-se que são necessárias políticas de fomento econômico e social talhadas para as necessidades específicas de regióes muito diferentes entre si, ganhando particular relevância o princípio de subsidiariedade (aumentando, consequentemente, a importância do nível local) e a articulação entre os vários níveis de políticas e instituiçóes (da escala europeia à local). Embora não mencionando especificamente a CT, é clara a relação entre a abordagem de base territorial que advoga e este princípio. $\mathrm{O}$ objetivo consiste em reduzir a ineficiência causada pela subutilização dos recursos, e em combater a exclusão social.

Todo este percurso conduziu a um reconhecimento mais generalizado da importância da componente territorial para o projeto europeu, colocando nas agendas política e mediática esta temática. Exemplo disso foi a inclusão, em dezembro de 2009 no Tratado de Lisboa, do princípio de ст enquanto $3^{\circ}$ pilar de atuação a par da Coesão Econômica e da Coesão Social, claramente sublinhando a preponderância deste princípio na definição de estratégias e na própria consolidação do projeto europeu (e uma visáo sistêmica do espaço europeu implica que cada Estado-Membro possua ideias claras sobre o caminho mais adequado a percorrer).

Atualmente, e de maneira a atualizar a dimensão estratégica dos documentos europeus de ordenamento do território, foi aprovada e lançada uma nova versão da Agenda Territorial - TA2020 (European Commission, 2011) com a dupla intenção de reforçar o papel da Ст enquanto novo paradigma de desenvolvimento do território europeu, e de tornar os territórios mais resilientes a desafios globais que, entretanto, surgiram ou alcançaram outras proporçóes, designadamente a crise econômica e financeira, os fenômenos demográficos (envelhecimento e migração), o despovoamento de determinadas áreas, as alteraçôes climáticas, a eficiência e a segurança energética, a vulnerabilidade de certas economias e comunidades locais e 
o papel das cidades enquanto motores de desenvolvimento (European Commission, 2011). É verdade que a versão de 2007 já efetuava uma análise destas questóes, mas nesta nova versão a profundidade e a abrangência são maiores, procurando tirar partido de um novo quadro institucional mais favorável (decorrente do Tratado de Lisboa) e articular-se com a nova estratégia Europe 2020.

Não sendo, portanto, uma preocupação totalmente nova, o princípio da CT surge no seio destas orientaçóes com o intuito generalizado de alcançar o desenvolvimento harmonioso de todos os territórios, valorizar sua diversidade e complementaridades e facultar a possibilidade da população tirar o melhor partido das características existentes em cada território. É certo que o Livro Verde e a abertura do processo de consulta pública sobre o mesmo procuraram clarificar o que se entendia por Ст e quais as políticas a tomar para se alcançar esse princípio, mas não é menos verdade que ainda se verifica alguma ambiguidade inerente ao seu conceito. Sendo notória a ausência de uma delimitação precisa do conceito, mas que do ponto de vista discursivo influencia claramente as agendas políticas (e científicas), qual então o seu valor acrescentado enquanto princípio integrante da formulação de políticas públicas? A discussão em torno desta questão será efetuada num duplo registro: primeiro, elencando as principais razóes que justificam a adoção do princípio de Ст na formulaçáo de políticas públicas no contexto atual e, depois, aprofundando conceitualmente este princípio para que se possam formular políticas públicas que caminhem no sentido de operacionalizá-la e promovê-la.

\section{A adoçáo do princípio de coesão territorial no contexto atual das políticas públicas}

A emergência das orientaçóes estratégicas de natureza politico-normativas -descritas na seção anterior- destacam a importância da dimensão territorial e das especificidades locais na formulação de políticas públicas, considerando o território náo só enquanto espaço físico de suporte às atividades existentes, mas, sobretudo, como um sistema social e institucional com múltiplas relaçóes, atividades e transaçôes econômicas. Com este enfoque, sublinha-se que os processos sociais e econômicos tomam forma num contexto espacial e estáo condicionados por fatores geográficos como a distância/proximidade, as características físicas (clima, topografia) e, ainda, a identidade de cada local. Contraria-se, portanto, a lógica que muitos autores defendiam no final do século passado: com fenômeno da globalização e o advento e a proliferaçáo das tecnologias de informação e comunicação, o espaço (ou a geografia) deixaria de ser relevante, na medida em que haveria uma perda de importância do acesso a fatores de produçáo tangíveis, em prol do interesse da disponibilidade de fatores de produção intangíveis, designadamente a informação e o conhecimento.

Estas questóes traçaram um caminho para a adoçáo do princípio de CT na agenda política, nomeadamente da $\mathrm{CE}$, na procura de um desenvolvimento harmonioso/ equilibrado do território, em que a dimensão territorial adquire uma maior preponderância. A título de exemplo, vejam-se os inúmeros estudos elaborados, seja, por exemplo, ao nível do ESPON, seja designadamente no âmbito da CE por intermédio 
dos relatórios de coesão, demonstrando os efeitos assimétricos que um conjunto de tendências atuais têm produzido, comprovando que os contextos territoriais podem, eles mesmos, serem amplificadores de desequilíbrios. Exemplos incluem a mobilidade e a pressão migratória, o envelhecimento demográfico, as alteraçóes climáticas e a eficiência energética, a globalização e competitividade econômica, as tecnologias de informação e comunicação, e a crescente importância das cidades (enquanto atores globais). Tendências que se tornam claramente um desafio para as políticas públicas, afetando quer a competitividade dos territórios quer os equilíbrios territoriais (numa lógica de igualdade de oportunidades), muitas vezes vistos como objetivos de certa forma conflituosos (Bertrand \& Peyrache-Gadeau, 2009). A adoção do princípio de Ст vem, precisamente, procurar lidar com esta questão, realçando as características específicas de cada território, não só ao nível dos problemas, mas também tendo em conta as oportunidades. Tal princípio revela uma nova abordagem, que une à ideia (sempre necessária) de combater disparidades regionais (essencialmente a partir de situaçôes problemáticas) uma lógica de valorização territorial, isto é, de concepção do território enquanto oportunidade.

Por outro lado, reconhecendo-se que as políticas públicas com impacto territorial são orientadas no âmbito da UE, quer pelas próprias políticas de ordenamento do território (através, por exemplo, da Agenda Territorial), quer por políticas setoriais, quer ainda, especificamente, pela Política de Coesáo (estabelecendo várias referências com significativo impacto no ordenamento do território), não se verifica ainda uma estreita articulação entre elas, podendo o princípio de CT servir de plataforma de articulação dessas políticas.

Acresce, no contexto atual de políticas públicas, outro motivo para a adoçáo do princípio de Ст. Não detendo competências formais no domínio do ordenamento do território, como já salientado, e apesar do contexto institucional favorável que hoje se verifica no seio da CE (em que a adoção do princípio de CT no Tratado de Lisboa é exemplo disso), é essencialmente através de reuniôes informais entre ministros de cada Estado-Membro que sáo debatidas, com alguma periodicidade, as questóes de ordenamento do território, procurando harmonizar e corresponsabilizar a implementação de princípios e desafios comuns e potenciais respostas. Neste sentido, como forma de harmonização e de difusão, a uE procura adotar mecanismos capazes de alterar culturas e modos de atuação territoriais nos Estados-Membros. Exemplos incluem a integração discursiva, construção de visóes espaciais partilhadas e práticas colaborativas transnacionais (Ferrão, 2010). E, de fato, certas orientaçóes (valores, identidades, metodologias, estratégias) têm sido induzidas por discursos hegemônicos e políticas da EU: o longo processo de trabalho técnico, científico e político conjunto que culminou com a aprovação do EDEC, constitui um bom exemplo desta questão, criando condiçóes para a harmonização de discursos e visôes partilhadas e a generalização de boas práticas. Da mesma forma, os debates que conduziram mais recentemente à adoção quer da Agenda Territorial e do seu $1^{\circ}$ Programa de Ação, quer do Livro Verde sobre a Coesão Territorial, contribuíram para consolidar este efeito EDEC, mobilizando diferentes comunidades nacionais e internacionais em torno de temas decisivos para a UE em geral, e para as políticas de ordenamento do território, em particular (Ferráo, 2010). Neste âmbito, a Cт tornou-se um conceito 
catalisador, em torno do qual, diversos valores e políticas (territoriais e não territoriais) têm gerado práticas discursivas.

De fato, o desenvolvimento de novos conceitos/representaçóes/metáforas no seio da UE produzem vários efeitos: i) chamam a atenção das entidades nacionais competentes do ordenamento do território para questôes/temáticas comuns; ii) ajudam a criar uma linguagem coletiva comum; iii) entram nos meios e nos debates políticos rapidamente, e com facilidade; e iv) procuram simplificar realidades complexas, pelo que constituem mensagens simples de uma ou duas palavras. Acresce que são conceitos que surgem da necessidade que as entidades sentem de formular quadros de referência, capazes de definir princípios orientadores para as políticas públicas (em geral) e o ordenamento do território (em particular). E, por isso mesmo, o aparecimento de conceitos como a CT representam a possibilidade de discutir as atuais tendências territoriais, e devem ser considerados como referenciais que permitem estruturar diferentes valores e culturas, e promover um diálogo intersetorial (Tatzberger, 2006; Servillo, 2010).

\section{Coesão territorial: uma interpretação processual}

O debate acadêmico e político em torno da CT tem sido amplo e incorpora inúmeras contribuiçóes do ponto de vista histórico (porque e como surgiu) e conceitual (seu propósito), seja ao nível da literatura acadêmica no domínio do ordenamento do território, da geografia e da economia, seja no nível de documentos oficiais e orientaçóes da CE. Embora, como conceito e objetivo político, este princípio tenha vindo a adquirir uma importância elevada, a consulta e análise desta extensa documentação mostra que o seu significado ainda não é consensual, dificultando a capacidade de lidar, de forma analítica e normativa, com o princípio. Mas, mais do que a procura de uma definiçáo precisa, importa clarificar o seu conteúdo efetivo e funcional, um percurso que também se encontra por trilhar.

Apesar de tudo, uma leitura sistémica deste corpo teórico e das questóes-chave que levanta, permite formalizar um conjunto de dimensóes analíticas subjacentes ao princípio de Ст, designadamente: i) reconhecer e lidar com a heterogeneidade territorial e a complexidade das dinâmicas territoriais; ii) estabelecer uma organização territorial que promova a intensificação das relaçóes interurbanas e a complementaridade de usos, funçóes e competências entre áreas urbanas e espaços rurais; iii) desenvolver intervençóes integradas assentes em sistemas de governança territorial.

$\mathrm{O}$ argumento que aqui se apresenta é o de que a percepção e o aprofundamento destas três dimensóes permitem clarificar o significado e lançar as bases para a operacionalização do princípio de Ст. Sua análise será efetuada tendo por base duas preocupaçóes: por um lado, procurando entender o que caracteriza cada dimensáo e clarificando de que forma estas se relacionam com a ideia de CT; por outro, pretendendo enquadrar e balizar a análise a efetuar, numa ótica de intervenção de políticas públicas. A análise culminará na apresentação, na próxima seçáo, de um quadro síntese de ideias-chave, que servirá como referencial para a formulação de políticas públicas tendo por base o princípio de CT. 
Dimensão heterogeneidade territorial

Lidar com a heterogeneidade territorial e a complexidade das dinâmicas territoriais significa, por um lado, reconhecer e combater a problemática associada às disparidades territoriais (amplamente divulgadas nos diversos relatórios produzidos, quer no âmbito da OCDE, quer no seio da CE) e, por outro, tirar partido da diversidade territorial.

A questão das disparidades desde cedo se constituiu em uma das principais preocupaçóes inerentes às políticas públicas - veja-se, por exemplo, o caso da Política de Coesão da UE e a atribuição dos fundos estruturais -, cujas intervençôes têm sido, de certa forma, ancoradas no desenvolvimento de estratégias de promoção de justiça social, um princípio normativo associado à equidade ou igualdade de oportunidades (Sen, 2010). A associação do conceito de justiça social a questóes territoriais por autores como Lefebvre (1969), Harvey (1973; 1996), Young (1990) e, mais recentemente, Soja (2010) e Fainstein (2010), veio, não só contribuir para um aprofundamento da noção de território, que náo deve ser encarado simplesmente enquanto objeto inanimado e passivo onde ocorrem processos sociais, como também chamar a atenção para a relação que existe entre esta dimensão e a sociedade. Aliás, é neste contexto que estes autores avançam com a noção de justiça espacial, em comum argumentando que a procura de justiça implica perceber a relação dialética entre, não só as condiçóes econômicas e sociais de diferentes grupos, mas também a geografia da injustiça, não sendo possível, portanto, compreender a questáo da equidade sem considerar de que forma os serviços, as oportunidades e o próprio poder institucional se encontram geograficamente distribuídos. Reconhecendo, entáo, que as disparidades territoriais merecem a maior atenção possível, torna-se crucial intervir sobre os territórios se os quisermos mais equitativos, devendo, neste sentido, a distribuiçáo de recursos, serviços e o seu acesso ser considerado um direito humano básico. E, de fato, esta foi, de algum modo, a primeira preocupação explícita por trás da noção de CT, do ponto de vista das políticas públicas da $\mathrm{CE}$, na procura do que se designa por um desenvolvimento territorial homogêneo da UE e em cada um dos Estados-Membros, como ficou explícito na narrativa histórica apresentada anteriormente.

Neste sentido, abraçar a problemática associada às disparidades territoriais implica lidar, de forma diferenciada, as áreas com as características geográficas (ecológicas, sociais e econômicas) especiais. Incute, pois, um juízo de discriminação positiva, atribuindo uma dimensão de justiça espacial à política pública e apelando à solidariedade, não só entre cidadáos, mas também entre territórios (Davoudi, 2009). Significa que a ação pública deverá ser diferenciada por uma questão moral e de acordo com as necessidades existentes (Boyne, Powell, \& Ashworth, 2001; Harvey, 1973), tratando de forma diferente realidades que são estruturalmente distintas, pelo que a soluçáo one-size-fits-all é insuficiente para lidar com a heterogeneidade territorial existente. Acresce que, esta ação pública diferenciada influencia igualmente a forma como em cada território se consegue lidar com os mais diversos desafios que a sociedade em geral enfrenta e enfrentará a curto e médio prazo. $\mathrm{O}$ documento Regions 2020 da CE (2008), que constitui um ponto de referência para a definição de orientações em matéria de Política de Coesão, dedica-se precisamente 
a esta questão, afirmando: “a Europa enfrentará nos próximos anos um número de desafios chave, incluindo: adaptação à globalização, às alteraçôes demográficas e climáticas, e ao desafio energético. Todas as regiôes Europeias serão afetadas. No entanto, cada um destes desafios exibe um padrão distinto" (p. 17).

Reconhecer a heterogeneidade territorial implica, assim, também tirar partido da diversidade dos territórios, ou seja, considerar as potencialidades e as fragilidades territoriais diferentes, o que consequentemente se traduz na análise das capacidades (bens, capitais, recursos...) existentes para formular políticas territorialmente diversificadas. Uma perspectiva que tem sido amplamente defendida nos tempos mais recentes é a que procura associar a ideia de que um território que tira partido da sua diversidade (e respectivas singularidades), é um território mais coeso e com maior potencial para se tornar mais competitivo e resiliente (Hamdouch, Depret \& Tanguy, 2011), ou seja, com maior capacidade de se antecipar e se adaptar, face às adversidades e às grandes tendências evolutivas. Está-se, aqui, perante o que na literatura se designa por valorizar o capital territorial, isto é, ser capaz de tirar partido dos elementos (características locais por vezes únicas) de que dispóe o território ao nível material (na forma de recursos naturais e culturais, bens públicos e a estrutura urbana em geral), e imaterial (no que respeita à capacidade relacional, ao empreendedorismo, à criatividade e à liderança) (Camagni \& Capello, 2010).

Ora, esta é a postura que a própria CE tem crescentemente defendido no âmbito da atribuição dos fundos estruturais e amplamente difundido, seja através da Política de Coesão, seja por intermédio da Estratégia Europa 2020. Esta mudança de orientação assenta, pois, no pressuposto de que a coesão náo decorrerá somente da concentração de recursos comunitários nas regióes menos desenvolvidas, postura tradicional de uma política redistributiva, como resposta a assimetrias regionais de desenvolvimento. A melhoria destas regióes exige investimento seletivo, qualificador e capaz de valorizar os seus recursos endógenos (Santinha et al., 2009). Por outras palavras, as intervençóes públicas devem deixar de ser tendencialmente desenhadas a partir de situaçóes problemáticas, para passarem (também) a considerar o território enquanto recurso fundamental para aumentar o leque de oportunidades de quem aí vive ou desenvolve a sua atividade, e enquanto fonte de qualidade de vida e bem-estar para as pessoas, e de conhecimento e bom desempenho para as organizaçóes (Ferrão, 2003).

\section{Dimensáo organização territorial}

A ideia subjacente a esta questão reside nas próprias palavras-chave que o Livro Verde menciona, designadamente: concentração (ultrapassar as diferenças de densidade, evitando concentraçóes excessivas de crescimento e facilitando o acesso à partilha dos benefícios proporcionados pelas aglomeraçóes existentes em todos os territórios); conectividade (melhorar o acesso a Serviços de Interesse Geral de forma socialmente e espacialmente equitativa); e cooperação (eliminar divisóes, na medida em que os problemas da conectividade e da concentraçáo só podem ser eficazmente resolvidos com a estreita cooperação entre todos os níveis de intervenientes). Poderá argumentar-se que a lógica por detrás da (des)concentraçáo, conectividade e cooperação está associada aos conceitos de desenvolvimento policêntrico e nova relação 
urbano/rural, que têm estado na base de grande parte das políticas de ordenamento do território desta última década e que surgem institucionalizados no EDEC.

A procura de uma Europa mais policêntrica e territorialmente equilibrada surge como resposta às persistentes disparidades territoriais verificadas no espaço europeu e às discussóes em torno do desenvolvimento territorial, que eram dominadas pelo pensamento convencional centro/periferia, em que a área mais desenvolvida economicamente era circunscrita por Londres, Paris, Miláo, Munique e Hamburgo (designado no próprio EDEC por Pentágono) e, a restante (periferia), necessitava de auxílio urgentemente. A noção de desenvolvimento policêntrico, não só introduz no debate uma interpretação mais sofisticada da organização territorial da Europa, sublinhando o potencial que outros centros (fora da área dominante) possuem (Meijers, Waterhout \& Zonneveld, 2007), como também pressupóe:

A convicção de que uma Europa mais forte necessita de um maior número de polos capazes de competir com sucesso nos mercados globais. Por outro lado, a ideia de que uma Europa mais equilibrada implica a existência de polos de valia europeia tanto no seu core como nas suas várias periferias. Finalmente, a defesa de que uma visão sistêmica do conjunto do espaço europeu permitirá recorrer às estratégias transnacionais de cooperação e complementaridade como meio ativo para valorizar de forma mais inteligente os recursos de toda a Comunidade (Ferrão, 2002, p. 33).

A lógica por detrás da adoção do desenvolvimento policêntrico, enquanto objetivo político favorável para o território Europeu, residiu igualmente no reconhecimento da Europa sentir os efeitos decorrentes do fenômeno de metropolizaçáo, associados, em parte, aos custos da sobre-concentração (poluição urbana, disponibilidade de solo, tempo de deslocaçáo, fragmentaçáo social...), e à perda de identidade territorial, aos quais se adicionam preocupaçóes com a procura de um desenvolvimento mais sustentável.

Alcançar um desenvolvimento mais policêntrico pressupóe uma organização territorial capaz de encorajar a cooperaçáo, isto é, apta para promover uma maior complementaridade entre as áreas urbanas, de forma a que estas desempenhem um papel estrutural ao criar espaços equilibrados e, ao mesmo tempo, desenvolver massa crítica ao nível econômico global, em uma perspectiva cosmopolita. Assim sendo, o desenvolvimento policêntrico baseia-se na ideia de que i) a organização do território assenta nas cidades, pelo que importa desenvolver a sua capacidade de atratividade e desenvolvimento, ii) as cidades constituem os nós com os quais se criará uma rede interurbana, cuja integração poderá ser intensificada com a constituição de redes de sinergia (cooperação entre áreas urbanas com perfis funcionais idênticos para a obtençáo de massa crítica suficiente e troca de experiências) e de complementaridade (cooperação entre áreas urbanas com perfis complementares de especializaçáo funcional e produtiva, próximas entre si) (Ferráo, 1998; Meijers et al., 2007) e iii) as interaçóes são facilitadas, quer via redes de infraestruturas físicas e virtuais (com recurso às tecnologias de informação e comunicação), quer por intermédio de relaçóes institucionais entre diferentes agentes, via estratégias conjuntas de desenvolvimento. 
Associado ao desenvolvimento policêntrico, surge a ideia da nova parceria urbano/rural, como uma forma de integrar as áreas rurais numa política de ordenamento conjunta, procurando uma situaçáo de win-win. De acordo com esta ótica, a dicotomia rural/urbano - em que se verificam determinadas características contrastantes tradicionais como isolamento versus acessibilidade, envelhecimento versus juventude, declínio versus dinamismo econômico, desertificação versus densidade populacional (Ferrão, 1998b) - é substituída por novos relacionamentos "retratando as interdependências funcionais e espaciais e a necessidade de promover uma maior integração e complementaridade territorial" (Marques, 2003, p. 507). Está-se, portanto, perante uma nova forma de definir políticas para o espaço rural - a que a OCDE (2006) designou por novo paradigma de desenvolvimento rural, e que visa o incremento de competitividade dessas áreas e a valorização dos recursos endógenos - e para o espaço urbano, cuja participação em lógicas reticulares sistêmicas e de proximidade (seja ao nível de fluxos de pessoas, bens e informação, seja por intermédio da prestação de serviços, seja ainda ao nível de políticas) pode constituir um fator, não só integrador, mas também alavancador de desenvolvimento para os dois espaços.

\section{Dimensão governança territorial}

O termo governança tem sido crescentemente usado nos domínios acadêmico e político, especialmente a partir da década de 70, e é atualmente considerado como fator crucial para a implementação de políticas públicas (veja-se, por exemplo, o relatório Barca, 2009). A emergência deste tema e o respetivo crescente interesse no contexto Europeu estáo, de certa forma, relacionados com a discussão em torno das transformaçóes dos Estados da Europa, quer em termos de articulação territorial, procurando a divisão de competências via descentralização/regionalização (Sharpe, 1993), quer em termos de processos de tomada de decisão, com o envolvimento e a mobilização de diferentes atores públicos e não públicos (Rhodes, 1997), quer ainda no que respeita à europeização de ideias, princípios, orientações e práticas no âmbito de políticas sob influência do processo de construção do projeto europeu, com impacto significativo em diversas estruturas organizacionais e administrativas dos diversos Estados-Membros (Ferrão, 1998a; 1998b).

É extensa a literatura que se debruça sobre a temática da governança no campo das ciências políticas, da sociologia política e das ciências econômicas, mas o seu conceito e os contextos onde é aplicado não são consensuais, pelo que não existe, a priori, um mecanismo de governança superior aos demais. Apesar de tudo, há um reconhecimento generalizado de que o termo governança se refere ao desenvolvimento de diferentes formas de atuaçáo, em que a fronteira entre os setores público e privado têm se atenuado (Rhodes, 1996; Stoker, 1998).

Uma análise da evolução histórica do papel do Estado na formulaçáo de políticas públicas permite verificar que há uma relaçáo estreita entre estes mecanismos e os princípios que caracterizam a governança pública. De fato, durante várias décadas (particularmente no período que decorre desde o pós 2a Guerra Mundial até a década de 80), verificou-se um consenso generalizado em torno do papel do Estado, considerado crucial para responder às necessidades dos cidadãos, não só para permitir a reconstrução 
do Estado-nação do ponto de vista econômico, mas também porque havia a necessidade de se envolver na gestáo de conflitos e concertaçóes entre classes e grupos sociais de forma a minimizar as desigualdades existentes. Neste período de intervenção direta do Estado na sociedade (Estado Providência ou de bem-estar), as despesas públicas eram interpretadas como um investimento coletivo (Hughes, 2003). Contudo, por um conjunto de razóes endógenas ao Estado (nomeadamente o aumento da despesa pública) e exógenas (como, por exemplo, a crise global desencadeada pelo aumento dos preços do petróleo), aliadas à eleição de Margaret Tatcher para o governo britânico (1979) e Ronald Reagan para os EUA (1980) - que apresentavam um discurso facilitador de diminuição de receitas (via redução dos impostos) e da despesa pública (através de mecanismos de privatização ou outras formas de contratos) - surgiram reformas que, de uma forma geral, introduziriam o movimento da Nova Gestão Pública e cujo período de afirmação decorre, sensivelmente, entre 1980 e o final dos anos 90 (Hughes, 2003; Silvestre, 2009). A ideia subjacente é a de usar as abordagens empresariais do sector privado no setor público e, consequentemente, tornar este mais magro e competitivo (através, por exemplo, do aumento do recurso a mecanismos tipo mercado, como a contratação externa, e da privatizaçáo de empresas públicas) (Lane, 2000). Apesar de tudo, foram várias as críticas apontadas a este movimento, associadas essencialmente à sua crença nas forças do mercado enquanto panaceia de todos os problemas e enquanto mecanismo capaz de representar o interesse social geral, pelo que se procurou uma nova agenda reformista, de certa forma, já visível na transição do século. Apesar de apresentar alguns pontos de continuidade com a Nova Gestáo Pública (realçando os mecanismos de mercado e as parcerias público-privadas como fatores-chave para a reforma administrativa), neste novo período, procura-se náo enfatizar a importância da competição, mas antes realçar os benefícios da colaboração, designadamente entre Estado, Mercado e Sociedade Civil (Newman, 2002). Esta diferença implica (potencialmente) alteraçóes na lógica de tomada de decisão e nas relaçôes interinstitucionais, sublinhando-se a necessidade de uma maior e melhor integração horizontal (entre setor público, setor privado e $3^{\circ}$ sector) e vertical (entre as administraçôes central, regional e local e entre quem define as políticas e quem é afetado por suas decisóes) (Denhardt \& Denhardt, 2007).

Ora, se a este contexto de mudança se associa a dimensão territorial, fica-se na presença de um quadro de governabilidade territorial mais integrado e estratégico, assente na interação e cooperação de diferentes atores e na coordenação de diferentes políticas (de base territorial e setoriais) em torno de uma agenda territorial comum (Ferrão, 2010). Autores como Feio e Chorincas (2009) argumentam que a governança territorial engloba a:

Capacidade de os atores públicos e privados de um determinado território conseguirem: i) construir um 'consenso organizacional', envolvendo diferentes atores, de forma a definir objetivos e metas comuns; ii) acordar a contribuiçấo de cada ator para a realização dos objetivos previamente definidos e iii) acordar a visão comum para o futuro do território (p. 140).

A noção de governança territorial está, portanto, associada à ideia de uma articulação mais eficiente, quer entre diferentes níveis de administração (ideia de governança multinível ou de cooperação/coordenação vertical, da escala europeia à escala 
local, a que está associado o princípio de subsidiariedade), quer entre entidades/ atores do mesmo nível (ideia de cooperação/coordenaçáo horizontal entre diversos atores, incluindo esferas pública, privada e terceiro setor), questóes decisivas para a formulação de políticas e construção de estratégias coletivas territoriais (Botka, 2009; Feio \& Chorincas, 2009; Janin Rivolin, 2010).

Esta cooperação institucional, seja via repartição vertical de atribuiçóes e competências numa ótica de subsidiariedade, seja via cooperação entre atores baseada numa visão partilhada sobre um mesmo território, pressupôe também abordagens articuladas e integradas das várias dimensóes setoriais, ou seja, subentende a procura de coerência de políticas, também estas baseadas numa visão partilhada sobre um mesmo território. Esta ideia de articular, integrar e territorializar as políticas públicas - incorporando a dimensão territorial nas políticas setoriais e articulando estas com as políticas de base territorial, contribuindo-se assim para uma maior sinergia entre diferentes políticas e para a maximização dos seus impactos territoriais - resulta do fato de as decisóes políticas serem tomadas essencialmente de um ponto de vista setorial e de forma desarticulada com as políticas territoriais. Esta é uma questão mencionada por vários documentos de orientaçáo política da $\mathrm{CE}$, sendo sublinhado que a articulação, integração e territorialização das políticas públicas tornam-se cruciais, quer para uma maior eficiência das próprias políticas, quer para tornar os territórios mais resilientes, capazes de se anteciparem e adaptarem às grandes tendências evolutivas e impactos de aspecto econômico, social, ambiental ou mesmo político. Tal implica considerar o território enquanto contexto diferenciador de políticas sectoriais, tornando-as consequentemente mais sensíveis ao território, e enquanto referência para a coordenação de políticas públicas, constituindo as políticas de base territorial um referencial estratégico que dá inputs importantes às políticas setoriais. É neste contexto que o território passa a ser considerado o lugar, por excelência, de articulação e racionalidade de políticas públicas (Feio \& Chorincas, 2009), reforçando a visibilidade, a legitimidade e a eficácia das políticas de base territorial, por um lado, e fomentando a simbiose entre as políticas setoriais sensíveis ao território e entre estas e as políticas de base territorial, por outro, tornandoas mais capazes de sustentar processos de desenvolvimento territorial.

\section{Comentário final e apresentação de quadro síntese}

A incursão histórica e teórica, e a reflexão aqui apresentadas em torno da CT mostram que este princípio é hoje amplamente reconhecido, tanto na arena política como no debate acadêmico, enquanto novo paradigma de desenvolvimento, tornando-se um veículo catalisador e atuando inclusive como referência normativa e cognitiva favorável ao processo de integração europeia. Mas, porque a adoção deste princípio vem acrescentar valor à tomada de decisão política? Em primeiro lugar, pelo sentido de coesão, isto é, pela promoção de ligaçôes e relaçôes fortes entre indivíduos ou instituiçóes para alcançar finalidades comuns, através, por um lado, de um maior equilíbrio social e econômico, na dupla ótica de distribuição de recursos e de participação nos processos de tomada de decisão, e, por outro, de uma afetação de recursos mais eficiente, valorizando a diversidade e a singularidade. Em segundo 
lugar, pela importância da dimensão territorial que completa o próprio conceito de coesão: a própria CE vem acrescentar esta componente na sua Política de Coesão aos outros objetivos de coesão social e econômica, o que, num período de particular importância devido à atribuição de fundos comunitários para o pós-2013, vem introduzir uma racionalidade adicional aos processos de tomada de decisão. Contudo, a abrangência e a falta de consenso, não só em torno do seu significado, mas, sobretudo, no que respeita ao seu conteúdo efetivo e funcional, têm dificultado a capacidade de utilizar este princípio nos processos de tomada de decisão. Ora, foi este mesmo o principal propósito do presente texto: avançar com um possível caminho para tornar o princípio de Ст mais compreensível e operacional, em uma ótica de intervenção de políticas públicas.

As dimensóes analíticas aqui aprofundadas - heterogeneidade territorial, organização territorial e governança territorial - procuram, em conjunto, contribuir para uma melhor percepção do conceito em discussão, delineando um percurso analítico e normativo para alcançar o desenvolvimento harmonioso de todos os territórios (isto é, diminuir/prevenir as disparidades territoriais, tornando-os mais homogêneos internamente e com inter-relaçóes equilibradas), a valorização da sua diversidade e complementaridades e a possibilidade da população tirar o melhor partido das características existentes em cada território, aliada a uma capacidade de interação e cooperação de diferentes agentes e políticas distintas (de base territorial e setoriais). O Quadro 1 sumaria estas dimensóes analíticas decorrentes da interpretação efetuada do princípio de $\mathrm{CT}$, visando criar um referencial que permita identificar e selecionar possíveis critérios de intervenção de políticas públicas. OEURE 
QUADRO 1 | Dimensóes analíticas do princípio de coesão territorial e respectivos componentes de intervenção

\begin{tabular}{|c|c|c|c|}
\hline \multicolumn{2}{|c|}{ COMPONENTE ANALÍTICA } & \multicolumn{2}{|c|}{$\begin{array}{c}\text { COMPONENTE DE INTERVENÇÃO } \\
\text { (POLÍTICAS PÚBLICAS) }\end{array}$} \\
\hline DIMENSÔES & SUBDIMENSÓES & FINALIDADE & OBJETIVOS \\
\hline \multirow{4}{*}{$\begin{array}{l}\text { Heterogeneidade } \\
\text { Territorial }\end{array}$} & \multirow{2}{*}{ Disparidades } & \multirow{2}{*}{ Justiça espacial } & $\begin{array}{l}\text { Combater a marginalização de pessoas } \\
\text { em contextos territoriais específicos }\end{array}$ \\
\hline & & & $\begin{array}{l}\text { Tornar os territórios mais } \\
\text { resilientes }\end{array}$ \\
\hline & \multirow{2}{*}{ Diversidade } & \multirow{2}{*}{$\begin{array}{l}\text { Valorização do } \\
\text { capital territorial }\end{array}$} & $\begin{array}{l}\text { Criar oportunidades a partir dos ativos } \\
\text { específicos de cada território }\end{array}$ \\
\hline & & & $\begin{array}{l}\text { Promover a identidade territorial como } \\
\text { fator de unidade/diferenciaçáo }\end{array}$ \\
\hline \multirow{6}{*}{$\begin{array}{l}\text { Organização } \\
\text { Territorial }\end{array}$} & \multirow{3}{*}{$\begin{array}{l}\text { Sistema Urbano } \\
\text { (policentrismo) }\end{array}$} & \multirow{3}{*}{$\begin{array}{l}\text { Desenvolvimento } \\
\text { urbano equilibrado e } \\
\text { em rede }\end{array}$} & $\begin{array}{l}\text { Desenvolver capacidades de } \\
\text { atratividade e competitividade dos } \\
\text { centros urbanos }\end{array}$ \\
\hline & & & $\begin{array}{l}\text { Promover a complementaridade } \\
\text { funcional interurbana (massa crítica } \\
\text { em rede) }\end{array}$ \\
\hline & & & $\begin{array}{l}\text { Estimular uma cultura de cooperação } \\
\text { estratégica interurbana }\end{array}$ \\
\hline & \multirow{3}{*}{$\begin{array}{l}\text { Urbano/rural } \\
\text { (parceria urbano- } \\
\text { rural) }\end{array}$} & \multirow{3}{*}{$\begin{array}{l}\text { Integração territorial } \\
\text { de proximidade }\end{array}$} & $\begin{array}{l}\text { Reforçar as relaçóes funcionais e o } \\
\text { desenvolvimento de redes (fluxos) entre } \\
\text { os centros urbanos e as áreas rurais }\end{array}$ \\
\hline & & & $\begin{array}{l}\text { Desenvolver mecanismos de } \\
\text { interdependência e de } \\
\text { complementaridade entre centros } \\
\text { urbanos e áreas rurais }\end{array}$ \\
\hline & & & $\begin{array}{l}\text { Estimular uma cultura de } \\
\text { participação em lógicas reticulares } \\
\text { sistêmicas e de proximidade }\end{array}$ \\
\hline \multirow{5}{*}{$\begin{array}{l}\text { Governança } \\
\text { Territorial }\end{array}$} & \multirow{2}{*}{$\begin{array}{l}\text { Coordenação } \\
\text { vertical }\end{array}$} & \multirow{2}{*}{$\begin{array}{l}\text { Governança } \\
\text { multinível }\end{array}$} & $\begin{array}{l}\text { Clarificar e articular a repartição } \\
\text { vertical de atribuiçóes e competências } \\
\text { (ótica de subsidiariedade) }\end{array}$ \\
\hline & & & $\begin{array}{l}\text { Melhorar a capacidade de coordenação } \\
\text { e governabilidade entre diferentes } \\
\text { escalas de intervençáo }\end{array}$ \\
\hline & \multirow{3}{*}{$\begin{array}{l}\text { Coordenação } \\
\text { horizontal }\end{array}$} & \multirow{3}{*}{$\begin{array}{l}\text { Cooperação } \\
\text { institucional e } \\
\text { coerência de políticas }\end{array}$} & $\begin{array}{l}\text { Desenvolver formas de cooperação } \\
\text { entre diversos atores baseada numa } \\
\text { visáo partilhada sobre um mesmo } \\
\text { território }\end{array}$ \\
\hline & & & $\begin{array}{l}\text { Desenvolver formas de discussão e } \\
\text { participação ativa dos cidadãos nos } \\
\text { processos de tomada de decisão }\end{array}$ \\
\hline & & & $\begin{array}{l}\text { Desenvolver abordagens articuladas, } \\
\text { integradas e territorializadas das várias } \\
\text { políticas públicas }\end{array}$ \\
\hline
\end{tabular}

FONTE ELABORAÇÃ́O PRÓPRIA 


\section{Referências bibliográficas}

Albrechts, L. (2001). In pursuit of new approaches to strategic spatial planning. A European perspective. International Planning Studies, 6(3), 293-310. doi: $10.1080 / 13563470120026514$

Atkinson, R. (2001). The emerging 'urban agenda' and the European spatial development perspective: towards an Eu urban policy? European Planning Studies, 9(3), 385-406.

Bertrand, N. \& Peyrache-Gadeau, V. (2009). 'Cohésion sociale et cohérence territoriale' quel cadre de réflexions pour l'aménagement et le développement? Géographie, Économie, Société, 11, 85-91. Disponível em www.cairn.info/revue-geographie-economiesociete-2009-2-page-85.htm

Böhme, K. (1998). A Northern View on EsDp. North, 4/5, 31-34.

Boyne, G.; Powell, M. \& Ashworth, R. (2001). Spatial equity and public services: an empirical analysis of local government finance in England. Public Management Review, 3(1), 19-34. doi: 10.1080/14719030122423

Camagni, R. \& Capello, R. (2010). Macroeconomic and territorial policies for regional competitiveness: an eu perspective. Regional Science Policy \& Practice, 2(1), 1-19. doi: 10.1111/j.1757-7802.2010.01016.x

Davoudi, S. (2009). Territorial cohesion, European social model and transnational cooperation. En J. Knieling \& F. Othengrafen (Eds.), Planning cultures in Europe. Decoding cultural phenomena in urban and regional planning (pp. 269-279). Aldershot: Ashgate.

Denhardt, J.V. \& Denhardt, R.B. (2007). The new public service: serving, not steering. New York: M. E. Sharpe.

Fainstein, S. (2010). The just city. Ithaca, NY: Cornell University Press.

Faludi, A. (2009). Territorial cohesion under the looking glass: Synthesis paper about the history of the concept and policy background to territorial cohesion. Recuperado de sito Web de European Commission, Regional Policy-Infogerio: http://ec.europa.eu/regional_ policy/archive/consultation/terco/pdf/lookingglass.pdf

Faludi, A. (2010, julio). Territorial cohesion post-2013: to whomsoever it may concern. Artículo presentado en 24th AEsop Annual Conference, Delft University of Technology, Otb Research Institute for the Built Environment, Finland. Disponível en http://bit. ly/1dK39rN

Feio, P. \& Chorincas, J. (2009). Governação territorial e inovação das políticas públicas. Prospectiva e Planeamento, 16, 137-157. Disponível em http://bit.ly/197J29m

Ferráo, J. (1998a). Red urbana, instrumento de equidad, cohesión y desarrollo. EURE, 24(71), 75-90. Disponível em http://bit.ly/15RxmEo

Ferráo, J. (1998b). Reconstruir o interior destruindo a interioridade: para uma estratégia activa de inclusão de actores. En Presidência da República (Ed.), Perspectivas de desenvolvimento do Interior. Lisboa: Presidência da República e Imprensa Nacional Casa da Moeda. Disponível em http://bit.ly/15thOVq

Ferrão, J. (2002). Policentrismo e coesão territorial: um novo papel para as regióes? Revista Europa - Novas Fronteiras, 12, 31-35. Disponível em http://bit.ly/154p7E3 
Ferrão, J. (2003). Para uma nova relação entre território, competitividade e acção pública. A democracia econômica como fonte de criação de valor. En Grupo Parlamentar do Partido Socialista (Ed.), Novas Politicas para a Competitividade (pp. 123-135). Oeiras: Celta Editora.

Ferrão, J. (2004). A emergência de estratégias transnacionais de ordenamento do território na Uniáo Europeia: reimaginar o espaço europeu para criar novas formas de governança territorial? EURE, 30(89), 43-61. Disponível em http://bit.ly/18sLyro

Ferrão, J. (2010). As condiçôes sociais de funcionamento da política pública de ordenamento do território. Programa de Investigação, provas de habilitação para o exercício de funções de coordenação científica, Instituto de Ciencias Sociales, Universidad de Lisboa, Portugal.

Hamdouch, A.; Depret, M. \& Tanguy, C. (2011, abril). Globalisation and territorial resilience: a suggested approach and preliminary insights from 3 case studies. Trabalho apresentado na The RSA Annual International Conference, Newcastle-upon-Tyne, uK.

Harvey, D. (1973). Social justice and the city. London: Edward Arnold and The Johns Hopkins University Press.

Harvey, D. (1996). Justice, nature and the geography of difference. Malden, MA: Blackwell.

Hughes, O. (2003). Public management and administration: An introduction. New York: Palgrave Macmillan.

Ionica, D. (2007). The territorial dimension of the Cohesion Policy. Romanian Economic Journal 10(25), 201-220. Disponível em http://bit.ly/1aYj4GJ

Janin Rivolin, U. (2010). EU territorial governance: learning from institutional progress. European Journal of Spatial Development, 1-28. Disponível em http://bit.ly/1bOkrGb Jouen M. (2008). Territorial cohesion: from theory to practice. Paris: Notre Europe.

Lane, J. (2000). New public management. London: Routledge.

Lefebvre, H. (1969). O direito à cidade. São Paulo: Editora Documentos.

Marques, T. (2003). Dinâmicas territoriais e as relaçôes urbano-rurais. Revista da Faculdade de Letras - Geografia, 29(1), 507-521. Disponível em http://ler.letras.up.pt/uploads/ ficheiros/326.pdf

Martin, P. (2003). Public policies and economic geography. En B. Funck \& L. Pizzati (Eds.), European integration, regional policy and growth (pp. 19-32). Washington DC: The International Bank for Reconstruction and Development/The World Bank.

Meijers, E.; Waterhout, B. \& Zonneveld, W. (2007). Closing the Gap: Territorial cohesion through polycentric development. European Journal of Spatial Development, 24, 1-24. Disponível em http://bit.ly/12BzyvK

Newman, J. (2002). The new public management, modernization and institutional change: Disruptions, disjunctures and dilemmas. Em K. McLaughlin, S. Osborne \& E. Ferlie (Eds.), The New public management: Current trends and future prospects (pp. 77-92). London: Routledge.

Rhodes, R. (1997). Understanding Governance: Policy Networks, Governance, Reflexivity and Accountability. Buckingham: Open University Press.

Rhodes, R.(1996). The New Governance: Governing without Government. Political Studies, 44, 652-667. doi: 10.1111/j.1467-9248.1996.tb01747.x

Richardson, T. \& Jensen, O. (1999). The Trouble with the ESDP. NORTH, 10(6), 11-16. 
Salez, P. (2009). How Europe comes to spatial planning: from the birth of regional policy to the Green Paper on territorial cohesion, the emergence of the Community as a player over more than 20 years. Em G. Baudelle, Y, Jean, M, Vanier, M. (Eds), L'Europe, aménager les territoires, Paris: A. Colin.

Salla, V. (2010). Political myth, mythology and the European Union. Journal of Common Market Studies, 48(1), 1-19. doi: 10.1111/j.1468-5965.2009.02039.x

Santinha, G.; Rodrigues, C. \& Almeida, A. (2009). Rumo a um novo ciclo de apoio comunitário: que impactos na definição de políticas territoriais de desenvolvimento local? $\mathrm{O}$ caso do Município de Arouca. Revista Inforgeo, 24, 45-65. Disponível em http://bit. ly/1bw5QjS

Sen, A. (2010). A ideia de justiça. Coimbra: Ediçôes Almedina.

Servillo, L. (2010). Territorial Cohesion Discourses: Hegemonic Strategic Concepts in European Spatial Planning. Planning Theory \& Practice, 11(3), 397-416. doi: $10.1080 / 14649357.2010 .500135$

Sharpe, L. (1993). The rise of meso-government in Europe. London: Sage.

Silvestre, H. (2009). Gestâo pública: modelos de prestação no serviço público. Lisboa: Escolar Editora.

Soja, E. (2010). Seeking spatial justice. Minneapolis: University of Minnesota Press.

Stead, D. \& Waterhout, B. (2008). Learning from the application of the ESDP: Influences on european territorial governance. disP, 44(172), 21-34. doi: 10.1080/02513625.2008.10557000

Stoker, G. (1998). Governance theory: Five propositions. International Social Science Journal, 50(155), 17-28. doi: 10.1111/1468-2451.00106

Tatzberger, G. (2006). Spatial visions, concepts and metaphors: their essential role in European spatial development and policy discourse. En L. Doria, V. Fedeli \& C. Tedesco (Eds.), Rethinking European Spatial Policy as a Hologram: actions, institutions, discourses (pp. 277-298). Aldershot: Ashgate.

Young, I. (1990). Justice and the politics of difference. Princeton, NJ: Princeton University Press.

\section{Documentos oficiales}

Barca, F. (2009). An agenda for a reformed cohesion policy: a place-based approach to meeting the European Union challenges and expectations (Independent Report prepared at the request of Danuta Hübner, Commissioner for Regional Policy). Recuperado del sitio web de European Parliament: http://bit.ly/15Rzw79.

Botka, M. (Coord.). (2009). Handbook on territorial cohesion - application of territorial approaches in developments supported by the public sector. Budapest: NFGM - VATI. Disponível em http://bit.ly/123M5gw

Commission of the European Communities (1991). Europa 2000. Perspectivas para o desenvolvimento do território da Comunidade. Luxemburgo: Serviço das Publicaçôes Oficiais das Comunidades Europeias.

Commission of the European Communities (1994). Europa 2000+. Cooperaçấo para o ordenamento do território Europeu. Luxemburgo: Serviço das Publicaçóes Oficiais das Comunidades Europeias.

Commission of the European Communities (2001). Governança Europeia - Um Livro Branco. $\operatorname{com}(2001) 428$ final, Bruxelas. 
Commission of the European Communities (2001). Unidade da Europa, solidariedade dos povos, diversidade dos territórios. Segundo relatório sobre a coesão econômica e social. Luxemburgo: Serviço das Publicaçôes Oficiais das Comunidades Europeias.

Commission of the European Communities (2004). Uma nova parceria para a coesão: convergência competitividade cooperação. Terceiro relatório sobre a coesão econômica e social. Luxemburgo: Serviço das Publicaçôes Oficiais das Comunidades Europeias.

European Observation Network for Territorial Development and Cohesion (2006). Territory matters for competitiveness and cohesion: facets of regional diversity and potentials in Europe. ESPON final Synthesis Report. Luxemburg: ESPON.

European Observation Network for Territorial Development and Cohesion (2007). Scenarios on the Territorial Future of Europe. ESPON Project 3.2. Luxemburg: ESPON.

Europa (s/a). Portal da Uniấo Europeia. A construção europeia através dos tratados. Disponível em http://europa.eu/legislation_summaries/institutional_affairs/treaties/index_pt.htm

European Commision. (2011, mayo). Territorial Agenda 2020 - Towards an Inclusive, Smart and Sustainable Europe of Diverse Regions [s.n.]. Gödöllő, Hungary: Autor. Disponível em http://bit.ly/15tkKRK

European Commission. (1999). European Spatial Development Perspective. Towards balanced and sustainable development of the territory of the European Union. Luxembourg: Office for Official Publications of the European Communities. Disponível em http://bit. ly/13T719Q

European Commission. (2004). Interim Territorial Cohesion Report (Preliminary results of ESPON and EU Commission studies). Luxembourg: Office for Official Publications of the European Communities. Disponível em http://bit.ly/13T7lH2

European Commission. (2007, mayo). Agenda Territorial da União Europeia. Reunión informal de Ministros de Desarrollo Urbano y cohesión territorial, Presidencia Alemana de Unión Europea, Leipzig, Alemania. Disponível em http://www.dgotdu.pt/ue/VFFAgenda\%20Territoria-_2009-1-10.pdf

European Commission. (2008a). Livro Verde sobre a Coesão Territorial Europeia - Tirar Partido da Diversidade Territorial [s.n.]. Bruselas: Autor. Disponível em http://www.dgotdu. pt/ue/LivroVerdeTC_pt.pdf

European Commission. (2008b). Regions 2020 - An Assessment of Future Challenges for EU Regions [s.n.]. Bruselas: Autor. Disponível em http://bit.ly/17qxnyt

European Commission. (2010). Europa 2020 - Estratégia para um crescimento inteligente, sustentável e inclusivo. [s.n.]. Bruselas: Autor. Disponível em http://bit.ly/13T7rhL

European Conference of Ministers responisble for Regional Planning (СЕмАт). (2000). Guiding principles for sustainable spatial development of the European continent [s.n]. Strasbourg: Autor. Disponível em http://www.bka.gv.at/DocView.axd?CobId=4747

Observatorio en Red de la Ordenación del Territorio Europeo (ESPON). (2007). Application and effects of the ESDP in the Member States. ESPON Project 2.3.1 [s.n]. Luxemburg: Autor. Disponível em http://bit.ly/13q246J

Organisation for Economic Cooperation and Development (oECD). (2001). Territorial outlook [s.n.]. Paris: Autor. Disponível em http://bit.ly/154rMxC

Organisation for Economic Cooperation and Development (oecD). (2006). The new rural paradigm: Policies and governance [s.n.]. Paris: Autor. Disponível em http://www3. unisi.it/cipas/ref/oECD_2006_Rural_Paradigm.pdf 
Organisation for Economic Cooperation and Development (oECD). (2009). Regions matter: Economic recovery, innovation and sustainable growth. [s.n.]. Paris: Autor.

The World Bank. (2009). World development report 2009: Reshaping economic geography. Washington DC: Autor. Disponível em http://bit.ly/197L2OV 